\title{
Behavioral Inferences of Tadawul Investor
}

\author{
Mohd I. M. Alnajjar ${ }^{1}$ \\ ${ }^{1}$ Business Administration Department, Al-Faisal University, Prince Sultan College for Tourism \& Business, \\ Kingdom of Saudi Arabia \\ Correspondence: Mohd I. M. Alnajjar, Business Administration Department, Al-Faisal University, Prince Sultan \\ College for Tourism \& Business, Kingdom of Saudi Arabia. Tel: 96-65-0447-7039. E-mail: \\ drnajjar2013@outlook.com
}

Received: September 22, 2013

Accepted: October 17, 2013

Online Published: November 20, 2013

doi:10.5539/ijbm.v8n24p17

URL: http://dx.doi.org/10.5539/ijbm.v8n24p17

\begin{abstract}
Behavioral finance significance has been widely accepted. This subject investigates the investor's irrational attitude while investing in stock market. This study provides a more detailed psychological decision making model for understanding the irrational behavior of investor while making investment in Tadawul. This study used a self-administered questionnaire for collecting the responses from 119 investors of Tadawul. Correlational stats are used to describe the association among the variables of the study.

Findings of this study confirms that investor behave irrationally. Positive association between risk perception and return expectations confirms the Value Function theory. Results of association between other study variables also confirm the hypotheses of the study. There is a negative relationship between information asymmetry and risk perception. Positive association of risk perception is shown with risk propensity and return expectations. Negative association of risk perception is shown with reinvestment intentions, investment performance and risk satisfaction.
\end{abstract}

Keywords: risk perception, risk propensity, return expectations, behavioral finance

\section{Introduction}

Global financial crisis is the reason behind serious losses faced by investors around the world. Investors suffered a lot and such hostile experiences are widespread in the different regions of the world. Therefore, now the investor is more careful about their investment decisions, not just because of intrinsic risk linked with the financial product but also because of unpleasant experience faced during global financial crisis. Now, a differential risk attitude of investor has been formed towards the investment decisionbecause of abhorrent personal experiences faced during global financial crisis. Therefore, it is needed to re-evaluate the high risk financial assets. So that, the differential risk attitude of investor could be adjusted while making their investment portfolio.

It is considered that today's investor is more knowledgeable and therefore, tries to incorporate all the obtained information while making investment portfolio decision. According to Efficient market hypothesis (EMH) by Fama (1970), investor is rational. Therefore, according to EMH, it is perceived that investor immediately incorporate all the newly available information while making portfolio or update his already built portfolio. In other words, the effect of all the released information or available information is reflected by the market. Thus, no one can earn abnormal returns ultimately, even when there is an asset price difference in the market, it will be adjusted at a normal level through arbitrage.

However, western studies are stating results contrary to EMH. According to Shiller (1981), Mehra \& Prescott, (1985) Leroy \& Porter (1981), Friedman (1953) and De Bondt \& Thaler (1985), markets are weak form efficient and therefore, market shows many irregularities e.g. new year's effect and weekend effect. So other ways were established in the market like portfolio insurance, diversification and indexing, for minimizing the investment risk (Wärneryd, 2001). In actual, EMH ignores the psychological aspect of the investor which considers the psychological decision making process of investor. Therefore, EMH is unable to completely explain the investor psychology involved in the investment related decision making process. There could be some other reasons behind the irrational decision of investor as Simon (1986) argues that investor's irrational behavior is the result of limited available resources to practice the available information.

According to the suggestion of Kahneman \& Tverskey (1979), Value Function should be used in place of expected 
utility theory and Prospects theory should be used along with the investor psychology for more thorough elucidation of the investor's psychological behavior while making investment decision. Value Function defines the gain or loss prospects with a differential risk attitude among the investors.Investor shows a different behavior while facing gain for ensuring the stability of profitsthrough risk adverse attitude. Contrary to this, investor takes more risk and become risk seeker while facing loses. So, situation is stimulus behind a differential investment behavior of investor towards risk.

Though, EMH argues in the favor of risk aversion behavior of investor while considering the risk factor but in reality investor behavior violates the EMH as shown by the above mentioned western studies. Therefore, it is needed to adopt a behavioral approach for financial market investigation. Barberis and Thaler (2002) argues about the importance of behavioral finance, as for comprehensively investigating the market phenomena use the behavioral finance because it considers the psychological decision making mechanism of investor behavior.

Market realized after the Asian Financial Crisis that investor risk taking behavior has change; therefore, financial institutions developed various financial products with different levels of risk associated with them by considering the large number of investor's choices. Different investors have different risk and return related preferences. Degree of risk associated with these products varies and naturally their returns also vary with their risk level. So, these different financial products are developed by considering the different investors psychology to meet their preferences. So, investor can choose any product in accordance with his risk and return related preference. Even so, past investment performance and advice by the investment advocates form the decision of investor regarding the buying decisions of products. Especially, risk perception plays a very important role in forming the reinvestment decision and return expectations of investor related to the investment. Particularly, after the global financial crisis, investor attitude towards the return expectations and reinvestment decision has significantly changed because of high risk perception.

Previously, many investigations have been done on the described matter. This study establishes a psychosocial model which empirically investigates the investor's behavior towards the investment satisfaction, investment performance, reinvestment decision and return expectations in the Kingdom of Saudi Arabia after the global financial crisis by considering the risk perception.

\section{Literature Review}

According to EMH, stock price fluctuation is the result of newly released information. When new information takes place in the market it changes the investor's risk and returns related expectations, which consequently changes the investment related decisions of the investor (Warneryd, 2001). There are also different types of information which prevails in the market which have a strong stimulus on the investor's decisions.

A plethora of research has been done to investigate the cause and effect relationship between stock price and variety of information available in the market by considering the expectations of investor (Warneryd, 2001). Diverse types of information is available in the market like improper management, interest rate and stock market policies (Song, 2003), but little is known about their effect on investor's risk perception. This meansthat diverse kind of information formulates variety of different decision making behaviors which depicts that information have strong stimulus for altering the investor's decision. Therefore, this study researches this abandoned area by particularly focusing on the improper management, interest rate and stock market policies as independent variable.

If all the information is not available to all the investors, this is called information asymmetry. Information asymmetry prevails in the market when the rules and regulations related to disclosure of information are inappropriate. Therefore, some of the investors have more information access then others. This information asymmetry becomes the motivation of irrational decision making. Thus, this is reason behind taking the information asymmetry as an independent variable for this study.

A model was developed by the Skitin \& Pablo (1992) which determines the risk behavior of investor, in which they postulates the risk propensity as vital part. Some other vital factors were also incorporated in their model which potentially impacts the perception of the risk of the investor.Results show that investors with low risk propensity are less exposed to risk comparative to the high risk tolerance investors. Therefore, investors high risk tolerance or low risk tolerance can be judged by assessing the level of portfolio risk (Cortor \& Chen, 2006). Thus, perception of risk of the investor is formed by their level of risk propensity.

Skitin \& Pablo (1992) describe the risk perception as it is an evaluation of risk in an uncertain investment environment. Certain inferences are developed by investor relating to the outcome of investment while making investment in an uncertain environment. There are certain stimuli behind the development of such inferences. 
Sometime, past investment experiences form the risk propensity of the investor. As long as the risk perception is concerned, risk propensity and some other variables like information type and information asymmetry, demographic variables form it. Demographic variables like gender and marital status has varying impact on the risk perception of the investor. Ronay \& Kim (2006) argues that male and female exhibited the same behavior towards risk but when they are analyzed in groups, male investors are perceived as risk seeker and female investors are perceived as risk averse. Study of Fellner \& Maciejovsk (2007) argues about the behavior of male and female at individual level and reported as female investors are conservative and risk averse at individual level as compare to male investors.

Investor have varying level of expectation by the investment like most commonly, investor expect that the investment made will generate high return by bearing low level of risk(Bodie, Kane \& Marcus, 2001). This points out that risk perception has the mediating role in the cognitive decision making process. As risk perception is an intuition about the probability of hostile consequences. So, this judgment could be consistent with actuality and could not be consistent with actuality because of certain social, situational and cultural factors (Vlek \& Stallen, 1981; Slovic, 1987; Douglas \& Wildavsky, 1982). Slovic (1987) described in his psychometric based model that people use "familiarity" and "controllability"to analyze the different kind of risky events.

Social, situational, cultural and psychological factors always have a significant effect on the investor's decision. Different factors have different impact on the decision. According to Diamond (1985), information disclosure significantly the cost of buying information which has a strong impact on the risk perception as appropriate information disclosure leads to low information asymmetry which significantly affected the risk perception of investor. Information disclosure solves the information asymmetry problem in the stock marketRoberts (2010). There are different for obtaining information and minimizing the problem of information asymmetry in the market. As, Xuan (2009) argues that CEO of the organizations obtain the internal information from the managers of the organization. Therefore, this kind of information has positive affect on the investment decision.

Capital market development is associated with the investment performance, investment satisfaction and reinvestment intension of the investor. If investor does not have sufficient information about the risk associated with different kinds of products, then he cannot make a good investment decision (Coval, Jurek \& Stafford, 2009). Therefore, having appropriate information about the risk associated with the products, is necessary for increasing the capitalization in the market. Availability of information forms the risk perception of the investor, which ultimately impacts the reinvestment intension of the investor.Investor's behavior can also be judged through economic incentive or level of satisfaction. Investment satisfaction is the state of utility maximization on future cash flows. Investment satisfaction and investment performance have a vital role in the capital market development. Therefore, this study considers both of them as dependent variables along with the reinvestment satisfaction and return expectations.

This study discovers the impact of various types of information on risk perception and how risk perception subsequently forms the investment satisfaction, investment performance, return expectations and reinvestment intensions. This study also considers the information asymmetry and risk propensity for analyzing its impact on the risk perception of the investors.

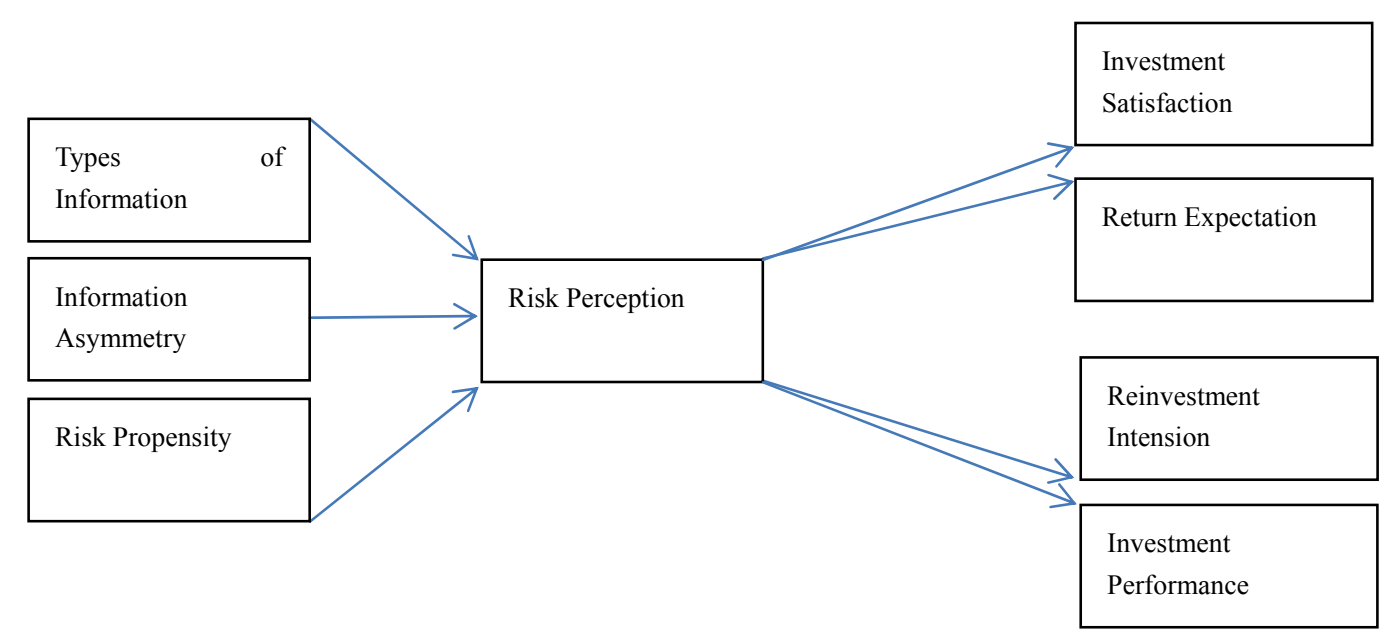

Figure 1. Psychological decision making model 
Following hypothesis are formed upon the basis of shown model:

Hypothesis 1 . Types of information are significantly correlated with the risk perception.

Hypothesis 2. Information asymmetry is positively correlated with investor's risk perception.

Hypothesis 3. Risk propensity is negatively correlated with risk perception.

Hypothesis 4. Risk perception is negatively correlated with reinvestment intensions, investment satisfaction and investment performance.

Hypothesis 5. Risk perception is positively correlated with investor's return expectations.

\section{Methodology}

This study uses the data from the investors of Tadawul (name of the Saudi Arabia stock exchange). Tadawul is the only stock exchange in Saudi Arabia. Therefore, all the brokerage houses deal with it only, hence, all the data is collected from the various brokerage houses except few responses. Few responses are collected directly by visiting the stock exchange and collected the responses from the investors who came to stock exchange for their personal affairs. Data is collected from the diverse investors group who belongs to the different regions of the country so that the perception of the investors from different regions could be summarized in one study. So that study results could be generalized to more than one regions of the country. This study distributed 160 questionnaires among the investors in three different regions of the country, out of which only 136 are received. Out of received 136 questionnaires, only 119 questionnaires are considered as useable. Response rate of collected questionnaires is $85 \%$ whereas the rate of considerable questionnaire with respect to the total dispersed questionnaires is $74.38 \%$.

Scale used for this study for measuring study items is taken from the various studies. As, the questionnaire items related to investment performance, investment satisfaction, information type, information asymmetry, reinvestment intentions and risk perception are used from Wang, Shi and Fan (2006) study. Risk propensity related items are used from Keil et al. (2000) study. Chou, Huang and Hsu (2010) study is used for obtaining the return expectations related scale for this study. Total of 8 variables related items are used in this study. Therefore, the questionnaire is comprised of total 10 questionnaire items along with 3 demographic variables namely; age, gender and marital status. All the items are tested on 5 point Likert scale.

This study used the self-administered questionnaire for gathering the responses of investors of Tadawul. Mean and standard deviation are used for describing the descriptive stats for the all the variables of this study. This study used the correlational stats for describing the correlation between the variables of the study.

\section{Results}

Randomly gathered data is analyzed in this chapter. Response bias for this is $25.62 \%$. Here is the result for demographic statistics.

Table 1. Gender

\begin{tabular}{cccccc}
\hline & Frequency & Percent & Valid Percent & Cumulative Percent \\
\hline \multirow{2}{*}{ Valid } & Male & 107 & 89.9 & 89.9 & 89.9 \\
& Female & 12 & 10.1 & 10.1 & 100.0 \\
& Total & 119 & 100.0 & 100.0 & \\
\hline
\end{tabular}

Table 1 is showing the response rate with respect to male and female respondents to the questionnaires. As shown in the table, male respondents are more with $89.9 \%$ as compare to the female respondents. Female respondents have response rate with the figure of $10.1 \%$. In the Saudi Arabia culture, female participation is business is very low. Therefore, they are also not in investment business. 
Table 2. Age

\begin{tabular}{cccccc}
\hline & Frequency & Percent & Valid Percent & Cumulative Percent \\
\hline Valid & $20-29$ & 8 & 6.72 & 6.72 & 6.72 \\
& $30-39$ & 59 & 49.57 & 49.57 & 49.57 \\
& $40-49$ & 49 & 41.17 & 41.17 & 41.17 \\
& $50-59$ & 3 & 2.52 & 2.52 & 100.0 \\
& Total & 119 & 100.0 & 100.0 & \\
\hline
\end{tabular}

Profile of participants with respect to their age is shown in the table 2. As shown in the table 2, response rate for the age group 30-39 is recorded as highest. Then on the second number, the high response rate is recorded of the investors between the age group of 40-49. Low participation is observed the respondents age group of 50-59 and the response rate of the investor's age group 20-29 is comparative higher than the age group of 50-59. Table 2 is showing the percentage response rate of all the participants with respect to their age group.

Table 3. Marital status

\begin{tabular}{cccccc}
\hline & & Frequency & Percent & Valid Percent & Cumulative Percent \\
\hline \multirow{2}{*}{ Valid } & Unmarried & 41 & 34.5 & 34.5 & 34.5 \\
& Married & 78 & 65.5 & 65.5 & 100.0 \\
& Total & 119 & 100.0 & 100.0 & \\
\hline
\end{tabular}

Table 3 is depicting the stats of the participants with respect to their marital status. Table 3 is showing that participation of married investors in the survey is higher than the unmarried investors. It is perceived that married investors are more experienced therefore they are more involved in the investment business. Therefore, this study is also showing that married investors are more participating in the current study survey. Statistics about their participation are shown in the below shown table.

Table 4. Descriptive status

\begin{tabular}{llll}
\hline & Mean & Std. Deviation & N \\
\hline Information Asymmetry & 3.1765 & .65674 & 119 \\
Information Type & 3.1457 & .72048 & 119 \\
Investment Satisfaction & 2.6092 & .72533 & 119 \\
Risk Perception & 3.0980 & 1.11348 & 119 \\
Reinvestment Intentions & 2.7227 & 1.11935 & 119 \\
Risk Propensity & 3.6218 & .72476 & 119 \\
Return Expectations & 3.0840 & .85944 & 119 \\
Investment Performance & 2.8992 & 1.51487 & 119 \\
\hline
\end{tabular}

Table 4 is showing the descriptive stats about the variable of the study. Mean value is showing the central tendency of the responses for each variable. Standard deviation is the measure of dispersion of responses from the mean value of responses. Mean value for information asymmetry, information type, risk perception, risk propensity and return expectations is above the 3 and mean value for investment satisfaction, reinvestment intentions and investment performance is below 3 but above 2.5 value. High value of dispersion of responses is recorded for investment performance otherwise risk perception and reinvestment intentions have the dispersion of response value above 1 otherwise all the remaining variables have dispersion of response value below 1 .

\subsection{Correlational Status}

Correlation between the study variables is defined by using the Pearson correlation. Different kinds of information namely; interest rate, improper management and variation in stock market policies are described under the information type variable and their cumulative relationship is described in this study. Table 5 is describing the correlations between the independent variables namely; information type, information asymmetry and risk propensity on the risk perception variable. 
Table 5. The findings between the independent variables and risk perception

\begin{tabular}{llll}
\hline & Pearson Correlation & Sig & $\mathrm{N}$ \\
\hline Information Type & 0.410 & 0.000 & 119 \\
Information Asymmetry & 0.251 & 0.000 & 119 \\
Risk Propensity & -0.013 & 0.010 & 119 \\
\hline
\end{tabular}

Table 5 is showing findings between the independent variables and risk perception. As shown in the table that information type is positively correlated with risk perception of the investor. This shows that different types of information are significantly important for investment decision. Three different types are used under the variable information type which means that if information about interest rate, improper management and market policies are significantly correlated with risk perception. With one unit change in information types, risk perception of investors will be change $41 \%$. Hypothesis of this study is confirmed through this positive relation.

Information asymmetry is also positively correlated with risk perception with the significant value of $25.1 \%$ and confirms the hypothesis of this study. This positive correlation is in line with the literature. With the increase in information asymmetry, risk perception of the investor also increases.

Relationship between risk propensity and risk perception is negatively formed in this study. This result is also in line with the literature as Cortor \& Chen (2006) argues that risk perception of investor is negatively affected by the risk propensity. As the risk tolerance of investor increase, risk perception of the investor is decreased. Investor becomes risk seeker with the increase in risk tolerance. All the results of relationship between independent variable and risk perception are confirming the hypothesis of this study.

Table 6 . The describing the relationship between risk perception variable and dependent variables

\begin{tabular}{llll}
\hline & Pearson Correlation & Sig & $\mathbf{N}$ \\
\hline Reinvestment Intensions & -0.345 & 0.000 & 119 \\
Investment Performance & -0.470 & 0.000 & 119 \\
Return Expectations & 0.360 & 0.000 & 119 \\
Investment Satisfaction & -0.104 & 0.001 & 119 \\
\hline
\end{tabular}

Table 6 is describing the relationship between risk perception variable and dependent variables of the study namely; reinvestment intensions, investment performance, return expectations and investment performance. Result of the study confirms the hypothesis 5 and hypothesis 6 . Hypothesis 5 states the negative relationship between risk perception and reinvestment intensions, which is confirmed with the negative value of $34.5 \%$. This means that with $1 \%$ increase in risk perception, reinvestment intensions of the investor will decrease by $34.5 \%$.

Investment performance and investment satisfaction are also negatively correlated with risk perception. With the $1 \%$ increase in risk perception, investment performance and investment satisfaction will be decrease by $47 \%$ and $10.4 \%$ respectively. Both the values are confirming the hypothesis 5 of this study.

Value Function defines the gain or loss prospects with a differential risk attitude among the investors. Investor shows a different behavior while facing gain for ensuring the stability of profits through risk adverse attitude. Contrary to this, investor takes more risk and become risk seeker while facing loses. This shows that while facing risk, return expectations of the investor will be positively correlated with the risk perception. As the risk perception will increase, return expectations of the investor will increase. This study confirms that after the global financial crisis, risk perception among the investors have increased significantly. Therefore, their return expectations have also increased.

\section{Conclusion}

This study provide a comprehensive psychological decision making model for the investors in KSA. This study attempts to supplement more behavioral factors in a psychological decision making model. This study approves the irrational behavior by empirically testing the study hypotheses and confirms that investor's behavior cannot be describes by simply considering the traditional finance theories. Most of the times, investor's behavior is irrational while investing in stock market. This study confirms the Value Function by showing a negative relationship between risk propensity and risk perception along with by showing the positive associationbetween risk perception and return expectations. This is also shown that different kinds of information like improper 
management, variation in stock market policies by government and variation in interest rate are correlated with the formation of risk perception of investor. Therefore, organization should more focus on their management and government should strengthen their regulations regarding stock market policy formation.

\section{References}

Byrne, K. (2005). How do consumers evaluate risk in financial products? Journal of Financial Services Marketing, 10, 1-36. http://dx.doi.org/10.1057/palgrave.fsm.4770171

Corter, J. E., \& Chen, Y. J. (2006). Do Investment Risk Tolerance Attitudes Predict Portfolio Risk? Journal of Business \& Psychology, 20, 369-381. http://dx.doi.org/10.1007/s10869-005-9010-5

Chou, S. R., Huang, G. L., \& Hsu, H. I. (2010). Investor Attitude and behavior towards Inherent Risk and Potential Returns in Financial Products. International Research Journal of Finance and Economics, 44, 16-30.

Corter, J. E., \& Chen, Y. J. (2006). Do investment risk tolerance attitudes predict portfolio risk? Journal of Business and Psychology, 3, 369-381. http://dx.doi.org/10.1007/s10869-005-9010-5

De Bondt. \& Werner, F. M. (1993). Betting on trends: Intuitive forecasts of financial risk and return. International Journal of Forecasting, 9(3), 355. http://dx.doi.org/10.1016/0169-2070(93)90030-Q

De Bondt, W., \& Thaler, R. (1985). Does the stock market overreact? Journal of Finance, 40, 793-808. http://dx.doi.org/10.1111/j.1540-6261.1985.tb05004.x

Fama, E. F. (1970). Efficient capital markets: a review of theory and empirical work. Journal of Finance, 25, 383-417. http://dx.doi.org/10.2307/2325486

Fellner, G., \& Maciejovsky, B. (2007). Risk Attitude and Market Behavior: Evidence from Experimental Asset markets. Journal of Economic Psychology, 28, 338-350. http://dx.doi.org/10.1016/j.joep.2007.01.006

Grable, J. E. (2000). Financial risk tolerance and additional factors that affect risk taking in every day money matters. Journal of Business and Psychology, 14, 625-630. http://dx.doi.org/10.1023/A:1022994314982

Ganzach, Y. (2002). Judging risk and return of financial assets. Organizational Behavior and Human Decision Process, 83, 353-370. http://dx.doi.org/10.1006/obhd.2000.2914

Harrison, T. (2003). Understanding the behavior of financial services consumers: A research agenda. Journal of Financial Services Marketing, 8, 6-9. http://dx.doi.org/10.1057/palgrave.fsm.4770102

Kahneman, D. (2003). Maps of Bounded Rationality: Psychology for Behavioral Economics. American Economic Review, 93, 1449-1475. http://dx.doi.org/10.1257/000282803322655392

Kahneman, D., \& Riepe, M. W. (1998). Aspects of investor psychology. Journal of Portfolio Management, 52-65.

Kahneman, D., \& Tversky, A. (1972). Subjective probability: A judgment of representativeness. Cognitive Psychology, 3, 430-454. http://dx.doi.org/10.1016/0010-0285(72)90016-3

Kahneman, D., \& Tversky, A. (1982). Prospect theory: An analysis of decision under risk. Econometric, 47, 263-291. http://dx.doi.org/10.2307/1914185

Lau, L. Y., \& Ranyard, R. (2005). Chinese and English probabilistic thinking and risk taking in gambling. Journal of Cross-Cultural Psychology, 36, 621-634. http://dx.doi.org/10.1177/0022022105278545

Lee, K. C., Chung, N., \& Kang, I. (2008). Understanding individual investor's behavior with financial information disclosed on the web sites. Behavior and Information Technology, 27, 219-227. http://dx.doi.org/10.1080/01449290601138146

Meir \& Statman. (2005). Normal Investors, Then and Now. Financial Analysts Journal, 61, 31-37. http://dx.doi.org/10.2469/faj.v61.n2.2713

Markus, H. R., \& Kitayama, S. (1991). Culture and the self: Implications for cognition, emotion, and motivation. Psychological Review, 98, 224-253. http://dx.doi.org/10.1037/0033-295X.98.2.224

Morris, M. H., Davis, D. L., \& Allen, J. W. (1993). Fostering corporate entrepreneurship: Cross-cultural comparisons of the importance of individualism versus collectivism. Journal of International Business Studies, 65-89.

Ronay, Richard \& Kim, Do-Yeong. (2006).Gender differences in explicit and implicit risk attitudes: A socially facilitated phenomenon. British Journal of Social Psychology, 45, 397-419. http://dx.doi.org/10.1348/014466605X66420

Skitin, S. B., \& Pablo. A. L. (1992). Re-conceptualizing the Determinants of Risk Behavior. Academy of 
Management Review, 17, 9-39. http://dx.doi.org/10.1086/296363

Skitin, S. B., \& Weingart, L. R. (1995). Determinants of risky decision-making behavior: A test of the mediating role of risk perceptions and propensity. Academy of Management Journal, 38, 1573-1582.

Simon, H. A. (1986). Rationality in psychology and economics. Journal of Business, 59, 209-224.

Spector, P. E., Cooper, C. L., Sanchez, J. L, Driscoll, M., \& Sparks, K. (2002). Locus of control and well-being at work: How generalizable are western findings? Academy of Management Journal, 45, 453-466. http://dx.doi.org/10.2307/3069359

Tversky, A., \& Kahneman, D. (1974). Judgment under uncertainty: Heuristics and biases. Science, 185, 1124-1131. http://dx.doi.org/10.1126/science.185.4157.1124

Weber, E. U., Blais, A. R., \& Betz, N. E. (2002). A domain-specific risk-attitude scale: Measuring risk perceptions and risk behaviors. Journal of Behavioral Decision Making, 15, 263-290. http://dx.doi.org/10.1002/bdm.414

Wang, C. F. (2003). The political impact-whether China's stock market is policy driving market.

Warneryd, K. E. (2001). Stock-market psychology: How people value and trade Stocks. Northampton. USA: MA, Edward Elgar.

Weber, E. U., Hsee, C. K., \& Sokolowska, J. (1998). What Folklore tells us about risk and risk taking? Cross-cultural comparisons of America, German, and Chinese Proverbs. Organizational Behavior and Human Decision Processes, 75, 170-186. http://dx.doi.org/10.1006/obhd.1998.2788

Wang, X. L., Shi, K., \& Fan, H. X. (2006). Psychological mechanisms of investor in Chinese Stock Markets. Journal of Economics Psychology, 27, 762-780. http://dx.doi.org/10.1016/j.joep.2006.06.007

\section{Copyrights}

Copyright for this article is retained by the author(s), with first publication rights granted to the journal.

This is an open-access article distributed under the terms and conditions of the Creative Commons Attribution license (http://creativecommons.org/licenses/by/3.0/). 